\title{
Dumping y medidas antidumping
}

${ }^{(1)}$ Daniel Mavila Hinojoza

${ }^{(2)}$ Antonio Luyo Quiroz

\begin{abstract}
RESUMEN
El dumping es la práctica de comercio en la cual una empresa vende un producto en el extranjero a precio inferior al que se vendería en su propio mercado nacional.

En el presente artículo se describen los parámetros principales que deben presentar una empresa 0 rama de producción que considere verse afectada ante precios dumping, enmarcados en las exigencias de los organismos que regulan la equidad del comercio internacional.
\end{abstract}

Palabras clave: GATT; WTO; OMC; Dumping; Antidumping.

DUMPING AND ANTI-DUMPING ACTIONS

\section{ABSTRACT}

The Dumping is the practice of trade in which a company sells a product abroad at less than that would be sold in its home market.

The present article describes the steps that should follow either a company or a branch of production, that might be affected by dumping prices.

Key Word: GATT; WTO; OMC; Dumping; Antidumping.

\section{INTRODUCCIÓN}

Una forma de garantizar que el comercio internacional de mercancías sea lo más equitativo posible es negociando normas de obligatorio cumplimiento, es en ese sentido que las normas de la OMC (Organización Mundial del Comercio - WTO: World Trade Organization), actualmente vigentes son el resultado de las negociaciones de la Ronda Uruguay, celebradas en los años 1986 y 1994, y que incluyeron la revisión del Acuerdo General sobre Aranceles Aduaneros y Comercio (GATT: General Agreement on Tariffs and Trade).

Desde 1995, el GATT actualizado es el documento referente para la OMC en lo relacionado al comercio de mercancías y sus anexos se centran en sectores específicos como agricultura, textiles, medidas antidumping, subvenciones, salvaguardias, etc. Es materia del presente artículo analizar las medidas antidumping y su manejo a nivel de una empresa o sector productivo supuestamente afectado por competencias "desleales" como podría ser considerado el dumping.

1. Docente Principal. Facultad de Ingeniería Industrial. Universidad Nacional Mayor de San Marcos.danielmavila@yahoo.es

2. Docente Asociado. Facultad de Ingeniería Geológica, Minera, Metalúrgica y Geográfica Universidad Nacional Mayor de San Marcos. E-mail: aluyoq@unmsm.edu.pe. 


\section{DUMPING}

En el marco que establece la Organización Mundial de Comercio; si una empresa exporta un producto a un precio inferior al que aplica normalmente en el mercado de su propio país, se dice que hace "dumping" (1). ¿Se trata de una competencia desleal? El Acuerdo de la OMC no emite ningún juicio al respecto, por el contrario se centra en la manera en que los gobiernos pueden o no reaccionar ante el dumping; establece disciplinas para las medidas antidumping y que a menudo se le denomina "Acuerdo Antidumping".

La normatividad peruana brinda al empresariado nacional las herramientas legales pertinentes para hacer valer sus derechos frente a esta práctica del comercio exterior, correspondiendo a INDECOPI (Instituto Nacional de Defensa de la Competencia y de la Protección de la Propiedad Intelectual) determinar, y ejecutar el procedimiento a seguir para estos casos particularmente a través de la Comisión de Dumping y Subsidios; INDECOPI es la institución peruana que supervisa que no se rompan las reglas básicas del mercado y que sean los mismos agentes económicos los que determinen los precios de mercado.

El dumping puede causar daño a una empresa o sector de la producción nacional, sea porque le resta participación en el mercado nacional por la caída de precios del producto, por la pérdida de puestos de trabajo, por la disminución de utilidades, por el incremento de la capacidad instalada ociosa, o, finalmente, por el cierre de las plantas industriales, entre otros perjuicios.

De otro lado, el acuerdo de la OMC autoriza a los gobiernos a adoptar medidas contra el dumping cuando se ocasione un daño genuino ("importante") a la rama de producción nacional competidora. Para poder adoptar estas medidas, se tiene que demostrar que existe dumping, calcular su magnitud (cuánto más bajo es el precio de exportación en comparación con el precio en el mercado del país del exportador), y que el dumping está causando daño o amenaza causarlo.

Particularmente, la República Popular China desea que todo país lo reconozca formalmente como una "Economía de Mercado" y que renuncie expresamente a su derecho de aplicar procesos de antidumping y al uso de salvaguardias discriminatorias. Sin estas dos condiciones, es difícil iniciar una negociación con China, los únicos países que han logrado iniciar negociaciones con China, tales como
Australia, Nueva Zelanda y Chile, han cumplido con las dos condiciones antes mencionadas. En el caso de la Asociación de Naciones del Sudeste Asiático (ASEAN), ocurrió lo mismo, con la salvedad de que el inicio de las negociaciones fue anterior al Protocolo de Adhesión de China a la OMC y es en el mismo Acuerdo de Bienes que ASEAN cumple con hacer el reconocimiento debido y comprometerse a no aplicar dichas cláusulas.

El Perú ya reconoció a China como "Economía de Mercado" a través de una nota diplomática, por lo que se ha comprometido formalmente a no aplicar las medidas de defensa comercial discriminatorias antes señaladas; las cuales se encuentran reguladas en el marco del ingreso de China a la OMC, a través de la firma de un Memorando de Entendimiento con este país.

Las consecuencias económicas de aceptar a un país como Economía de Mercado se circunscriben a las investigaciones de dumping y subsidios. Al no ser el precio de venta interno resultado de la libre interacción de la oferta y la demanda, la legislación de la OMC permite tomar como referente otros valores que aseguren un cálculo equitativo del margen del dumping, tales como el precio de exportación a un tercer país o la reconstrucción del precio de venta interno.

\section{NECESIDAD DE MEDIDAS ANTIDUMPING}

La existencia de daño se basará en pruebas positivas y comprenderá un examen objetivo: a) del volumen de las importaciones objeto de dumping $y$ del efecto de estas en los precios de productos similares en el mercado interno y b) de la consiguiente repercusión de esas importaciones sobre los productores nacionales de tales productos.

La determinación de la existencia de una amenaza de daño importante se basará en hechos y no simplemente en alegaciones, conjeturas o posibilidades remotas. La modificación de las circunstancias que daría lugar a una situación en la cual el dumping causaría un daño deberá ser claramente prevista e inminente. Al llevar a cabo una determinación referente a la existencia de una amenaza de daño importante, INDECOPI considerará, entre otros, los siguientes factores:

a) Una tasa significativa de incremento de las importaciones objeto de dumping en el mercado interno que indique la probabilidad de que aumenten sustancialmente las importaciones; 
b) Una suficiente capacidad libremente disponible del exportador o un aumento inminente y sustancial de la misma que indique la probabilidad de un aumento sustancial de las exportaciones objeto de dumping al mercado del importador, teniendo en cuenta la existencia de otros mercados de exportación que puedan absorber el posible aumento de las exportaciones.

c) El hecho de que las importaciones se realicen a precios que tendrán en los precios internos el efecto de hacerlos bajar o contener su subida de manera significativa, y que probablemente hagan aumentar la demanda de nuevas importaciones; $y$

d) Las existencias del producto objeto de la investigación.

Ninguno de estos factores por sí solos bastarán necesariamente para obtener una orientación decisiva, pero todos ellos juntos han de llevar a la conclusión de la inminencia de nuevas exportaciones a precios de dumping y de que, a menos que se adopten medidas de protección, se producirá un daño importante.

Existen varias formas de calcular si un determinado producto es objeto de dumping en grado importante o solo ligeramente con respecto a su valor normal, para el efecto se tienen tres métodos para calcular el "valor normal" del "producto similar". La expresión "producto similar" ("like product") significa un producto que sea idéntico, es decir, igual en todos los aspectos al producto de que se trate, o, cuando no exista ese producto, otro producto que, aunque no sea igual en todos los aspectos, tenga características muy parecidas a las del producto considerado.

El principal método para calcular el "valor normal" se basa en el precio del producto en el mercado del país del exportador, cuando no puede utilizarse este método, existen dos alternativas: el precio aplicado por el exportador en otro país o un cálculo basado en la combinación de los costos de producción del exportador, otros gastos y márgenes de beneficio normales.

El cálculo de la magnitud del dumping de un producto no es suficiente, las medidas antidumping solo se pueden aplicar si el dumping perjudica a la rama de producción del país importador, tal como se mencionó líneas arriba. Por lo tanto, ha de realizarse, en primer lugar, una investigación para evaluar los factores económicos que guardan relación con la situación de la rama de producción en cuestión. Si la investigación demuestra que existe dumping y que la rama de producción nacional sufre un daño, la empresa exportadora puede comprometerse a elevar su precio a un nivel convenido a fin de evitar la aplicación de un derecho de importación antidumping.

Las investigaciones antidumping han de darse inmediatamente por terminadas en los casos en que las autoridades determinen que el margen de dumping es insignificante (lo que se define como inferior al $2 \%$ del precio de exportación del producto). Se establecen asimismo otras condiciones, por ejemplo, las investigaciones tienen también que terminar si el volumen de las importaciones objeto de dumping es no significativo, en otras palabras, si el volumen procedente de un país es inferior al $3 \%$ de las importaciones totales de ese producto.

En lo que respecta al volumen de las importaciones objeto de dumping, INDECOPI tomará en cuenta si ha habido un aumento significativo de las mismas, en términos absolutos o en relación con la producción o el consumo del país importador. En lo tocante al efecto de las importaciones objeto de dumping sobre los precios, INDECOPI tendrá en cuenta si ha habido una significativa subvaloración de precios de las importaciones objeto de dumping en comparación con el precio de un producto similar del país importador, o bien si el efecto de tales importaciones es hacer bajar de otro modo los precios en medida significativa o impedir en medida significativa la subida que en otro caso se hubiera producido.

El efecto de las importaciones objeto de dumping se evaluará en relación con la producción nacional del producto similar cuando los datos disponibles permitan identificarla separadamente con arreglo a criterios tales como el proceso de producción, las ventas de los productores y sus beneficios. Si no es posible efectuar tal identificación separada de esa producción, los efectos de las importaciones objeto de dumping se evaluarán examinando la producción del grupo o gama más restringido de productos que incluya el producto similar y a cuyo respecto pueda proporcionarse la información necesaria.

La expresión "rama de producción nacional" se entenderá en el sentido de abarcar el conjunto de los productores nacionales de los productos similares, o aquellos en los que cuya producción conjunta constituyan una proporción importante de la producción nacional total de dichos productos. 


\section{CASO PRÁCTICO}

Producto: bolas y artículos similares para molinos de fundición de hierro o acero

Partida arancelaria: 7325910000

Supongamos que la empresa $A$ produce bolas forjadas de acero para molienda de minerales. La producción incluye bolas de diámetros: 1" - 1.5" - 2" - 2.5" - 3" - 3.5" - 4" y 5". Ver Figura N. 1.

La empresa $B$ produce bolas fundidas destinadas al mismo fin que las de la empresa $A$, además, ambas empresa son domiciliadas en el Perú; mientras que la empresa $\mathrm{C}$ fabrica bolas de acero fundidas, está domiciliada en un país extranjero $X$ y parte de su producción la vende en nuestro país; todas estas bolas son usadas para la molienda de minerales metálicos y no metálicos, tienen apariencia física similar y son comercializadas en el mismo mercado peruano.

La empresa extranjera C vende a US\$ 60 la tonelada precio de exportación, con un precio de US\$ 80 ; el costo en el mercado interno.

El margen de dumping, es decir, la diferencia entre el precio FOB de exportación y el precio de venta en el mercado interno del país $X$ a nivel $F O B$ se establece a partir de la diferencia entre el "valor normal" y el "precio de exportación", para el efecto se utiliza la siguiente fórmula:

$$
\begin{aligned}
& M D=\left(\frac{V n-P x}{P x}\right) \times 100 \\
& M D=\left(\frac{80-60}{60}\right) \times 100=33.33 \%
\end{aligned}
$$

Donde:

MD: Margen de dumping

Vn: Valor normal

Px: Precio de exportación.

Además, las ventas totales de bolas de acero de producción nacional, luego de crecer entre 2007 y 2008 , en el 2009 , disminuyeron en $30 \%$ con relación al año anterior, lo que coincidió con un significativo nivel de importaciones por parte de la empresa $\mathrm{C}$.

Con la información descrita, se podría concluir que existen pruebas suficientes para solicitar a INDECOPI para que aplique medidas antidumping basadas en que las bolas de acero fundidas producidas por la empresa $\mathrm{C}$ son similares a las bolas de acero elaboradas por las productoras nacionales A y B (bolas forjadas y bolas fundidas) en tanto todas estas bolas son usadas para la molienda de minerales metálicos, tienen apariencia física similar y son comercializadas en el mismo mercado; además, se evidencia la existencia de daño y de relación causal entre el daño y el dumping, pues dichas importaciones vienen afectando a la empresa descrita.

\section{CONCLUSIONES}

La práctica del dumping es consecuencia de una política empresarial de penetración y posicionamiento de mercados internacionales mediante una discriminación de precios, esto es, la colocación de excedentes de producción en un mercado externo o la exportación de productos a costos variables, considerando que los costos fijos los cubre el mercado local.

Es preciso distinguir el dumping de simples prácticas de venta a bajo precio derivadas de costes inferiores o de una productividad superior. El criterio fundamental no es la relación entre el precio del

Figura $\mathbf{N}^{\circ}$ 1. Molino de bolas para molienda de minerales metálicos y bolas de acero
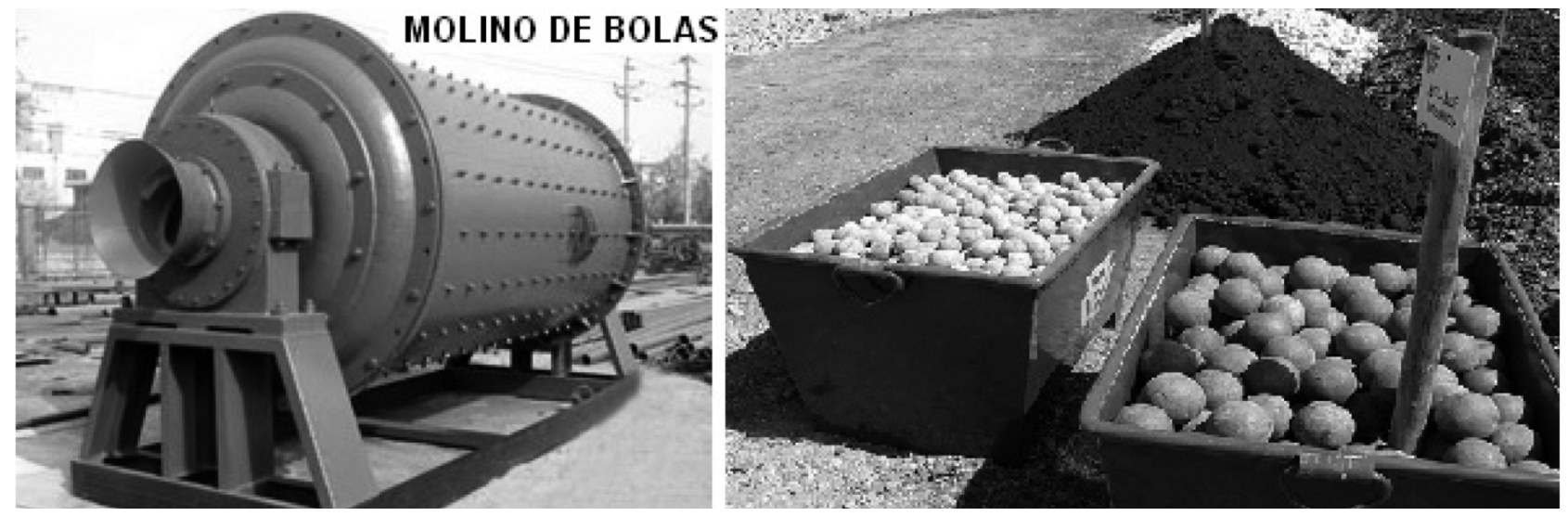
producto exportado y el del mercado del país de importación, sino la relación existente entre el precio del producto exportado y su valor normal.

El dumping no es una competencia desleal per se. Por ejemplo, una empresa que exporte a nuestro país un producto que no producimos a un precio inferior al de su país de origen, dado que en su país de origen ya cubrió sus costos fijos, beneficiará a nuestros consumidores.

La posibilidad que una empresa venda en el mercado externo a precios más bajos que en el mercado interno, depende del cumplimiento de las siguientes premisas, de lo contrario no sería viable una práctica de dumping:

a. Las características de la demanda en el país de destino deben ser distintas a las del país de origen. Por ejemplo, en los países en los que la demanda sea menos elástica, los exportadores podrán fijar precios relativamente más altos que en mercados con demandas más elásticas; y

b. No debe ser rentable la reventa de los productos por parte de los consumidores del país de desti- no al país de origen. El costo (en fletes, aranceles aduaneros, seguros, etc.) en que incurra un consumidor del país de destino en la reventa del producto debe superar el precio en el país de origen.

\section{REFERENCIAS BIBLIOGRÁFICAS}

1. Asociación de Naciones del Sudeste Asiático (ASEAN)

http://es.wikipedia.org/wiki/ASEAN

[Visitado: 16-04-2009].

2. Comisión de Dumping y Subsidios. http://www.indecopi.gob.pe/destacado-competencia-comisiones-dys-pres.jsp [Visitado: 10-02-2009].

3. Entender la OMC: los acuerdos antidumping, subvenciones, salvaguardias: casos imprevistos, etc.

http://es.wikipedia.org/wiki/ [Visitado: 14-03-2009] http://www.wto.org/spanish/thewto_s/whatis_s/ tif_s/agrm8_s.htm [Visitado 15-03-2009].

4. Reglamento sobre Medidas Antidumping y Compensatorias (D.S. N. ${ }^{\circ} 006$-2003 PCM). 